\title{
Prevalence, typology and clinical correlates of sexual dysfunction among men with alcohol dependence syndrome
}

\author{
Anil Kumar B.N. ${ }^{1}$, Shalini M. ${ }^{2}$, Sanjay Raj G. ${ }^{3}$, Prasannakumar D.R. ${ }^{4}$ \\ ${ }^{1}$ Dr. Anil Kumar Buruganahalli Nagendrappa, Assistant Professor, Department of Psychiatry, ${ }^{2}$ Dr. Shalini Mallanna, \\ Professor, Department of General Medicine, ${ }^{3}$ Dr. Sanjay Raj G., Senior Resident, Department of Psychiatry; all authors \\ are affiliated with Shridevi Institute of Medical Sciences and Research Hospital, Tumkur, India, ${ }^{4}$ Mr. Prasannakumar \\ D.R., Assistant Professor, Bapuji College of Nursing, Davanagere, India.
}

Address for Correspondence: Dr Anil Kumar Buruganahalli Nagendrappa, Assistant Professor, Department of Psychiatry, Shridevi Institute of Medical Sciences and Research Hospital, NH 4, Sira Road, Tumkur, Karnataka, India. Email id: anilkbn23@gmail.com

\begin{abstract}
Background: Chronic and persistent alcohol use is known to induce sexual dysfunction, but it is often unexplored and untreated in routine clinical practice. Objective: To study the prevalence and typology of sexual dysfunction and its clinical correlates among male patients seeking treatment for alcohol dependence. Materials and Methods: 60 male subjects (aged 18-50 years) meeting the criteria for alcohol dependence syndrome (ADS), according to DSM-IV were enrolled for the study. Data regarding socio- demographic and clinical details were recorded on a semi-structured proforma designed for the study. They were assessed for sexual dysfunction using a Sexual Dysfunction Checklist, constructed using items from the Diagnostic Criteria for Research (ICD-10) for sexual dysfunction and Arizona Sexual Experience Questionnaire (ASEX) and for severity of alcohol dependence using the Severity of Alcohol Dependence Questionnaire (SADQ). Results: $58.3 \%$ had one or more sexual dysfunction as per ASEX, the most common being inability to reach orgasm $(60 \%)$, dissatisfaction with orgasm $(58.3 \%)$ and erectile dysfunction $(56.7 \%)$. As per sexual dysfunction checklist, dissatisfaction with own sexual performance (58.3\%), anorgasmia (56.7\%) and erectile dysfunction $(53.3 \%)$ were the most common. Longer duration of alcohol consumption and dependence, high levels of intake and sever dependence appeared to be the most significant predictors of developing sexual dysfunction. Conclusion: SD is highly prevalent in patients with alcohol dependence and all domains of sexual functioning are affected. Anorgasmia is quite common in patients with alcohol dependence. Longer duration of consumption and dependence and heavy drinking proportionately increases the risk. Clinicians need to routinely evaluate sexual functioning in alcoholic patients and address the same.
\end{abstract}

Key words: Alcohol; Alcohol dependence syndrome; Sexual dysfunction.

\section{Introduction}

According to WHO Global Status Report on Alcohol and Health 2014, alcohol consumption in India has gone up. Around $11 \%$ of women and $32 \%$ of men over the age of 15 consume [1]. World Health Report in 2002 reported that $8.9 \%$ of the total burden of disease worldwide in 2000 was from the use of psychoactive substances [2]. Chronic and persistent alcohol use is known to induce sexual dysfunction (SD). It may leads

Manuscript received $26^{\text {th }}$ September 2016

Reviewed: $8^{\text {th }}$ October 2016

Author Corrected: $20^{\text {th }}$ October 2016

Accepted for Publication $31^{\text {st }}$ October 2016 to marked distress and interpersonal problems among couples [3]. A review by Grover et al. suggests that prevalence of SD has ranged from 40-95.2\% across the studies and long term use of alcohol is associated with $\mathrm{SD}$ in all most all domains of sexual functioning.

The common SDs reported in this review was erectile dysfunction (ED) followed by premature ejaculation (PME), retarded ejaculation and decreased sexual desire among men, and dyspareunia and vaginal dryness among women [4]. Association between high amount of 
alcohol consumption and long-term use and SD has been widely reported [5,6].

A World Health Organization cross-cultural study for alcohol done across eight countries reported that $12 \%$ males in the general population consumed alcohol prior to first sexual intercourse to get positive effect and to improve sexual pleasure [7]. However persistent use impacts sexual functioning negatively and leads to the onset of sexual dysfunction [8].

However, sexual dysfunction among alcohol dependent patients has not caught the attention of clinicians and researchers as much as other complications. As a result, sexual dysfunction is often neglected, unexplored and unattended in routine clinical care of patients. Yet, it is clinically highly relevant as it affects psychological well being in terms personal inadequacy, guilt, low self esteem, worthlessness, unsatisfying personal relationship with partner leading to marital conflicts. Research in this area is highly limited especially from Indian subcontinent.

The present study is carried out to look for the prevalence, typology and demographic and clinical correlates of sexual dysfunction among alcohol dependent male patients.

\section{Materials and Methods}

Subject selection-The study was conducted in Shridevi Institute of Medical Sciences and Research Hospital, a tertiary care centre in southern part of India. All male subjects presenting to hospital with alcohol related problems were recruited and they were enrolled into the study if they fulfil the following inclusion and exclusion criteria.

Inclusion criteria- Men aged 18-50 years who were married or having stable heterosexual partner atleast for last one year with diagnosis of alcohol dependence as per Diagnostic and Statistical Manual of Mental disorders, fourth edition (DSM-IV) [9] and dependent on alcohol for at least 1 year.

\section{Exclusion criteria}

- Patient in acute intoxication or acute withdrawal state.

- Concurrent presence of other Substance Dependence, according to DSM-IV, other than Nicotine.

- History of SD prior to the onset of substance use.

- Concurrent presence of chronic co-morbid medical illness which can cause sexual dysfunction (hypertension, diabetes mellitus, thyroid dysfunction, alcoholic liver disease, renal dysfunctions, cardiovascular and neurological disorders like stroke, spinal cord lesions, peripheral neuropathy. These were ruled out by the needed history, physical examination and investigations.

- Co-morbid psychiatric disorders: schizophrenia, delusional disorder, anxiety disorders and mood disorders including dysthymia. Subsyndromal cases of depression or anxiety were included in the study.

- Use of drugs affecting sexual function (antipsychotics, antidepressants, antihypertensives, steroids, disulfiram etc.)

Data collection and clinical evaluation- Ethical committee approval was obtained for the study. Patients with a clinical diagnosis of alcohol dependence syndrome as per DSM IV and meeting the inclusion and exclusion criteria were approached for participation in the study. They were explained about the nature of the study and patients willing to participate and providing informed consent were recruited. Socio- demographic details, history, general physical examination and mental status examination were recorded on a semistructured proforma designed for the study. Severity of alcohol dependence was assessed using the Severity of Alcohol Dependence Questionnaire (SADQ) [10]. They were assessed for the prevalence and typology of one or more sexual dysfunction experienced over the past 12 months using a Sexual Dysfunction Checklist, constructed using items from the Diagnostic Criteria for Research (ICD-10) [11] for sexual dysfunction and Arizona Sexual Experience Questionnaire (ASEX) [12]. Temporary and situational complaints were ignored.

\section{Results}

Socio-demographic profile- The analysis indicated that mean age at presentation was 38.38 years $($ S.D. $= \pm 7.477)$. Majority of the patients were Hindu (98.3\%), married (75\%), studied $10^{\text {th }}$ class and above (48.41\%), employed (83.3\%), belong to nuclear family $(51.7 \%)$, middle socio economic status $(56.7 \%)$ and rural background $(60 \%)$. Further details are given in Table 1. 
Table-1: Socio-demographic profile.

\begin{tabular}{|l|c|}
\hline Socio- demographic variable & $\mathbf{n}(\%)$ \\
\hline Mean age at presentation in years \pm S.D.) & $38.38 \pm 7.477$ \\
\hline Education & $7(11.7)$ \\
\hline Illiterate & $11(18.3)$ \\
\hline Primary $\left.6^{\text {th }}\right)$ & $13(21.7)$ \\
\hline Middle $\left(8^{\text {th }}\right)$ & $16(26.7)$ \\
\hline High school $\left(10^{\text {th }}\right)$ & $13(21.7)$ \\
\hline College and above & \\
\hline Current occupational status & $50(83.3)$ \\
\hline Employed & $10(16.7)$ \\
\hline Unemployed/ Home maker & \\
\hline Family type & $29(48.3)$ \\
\hline Joint & $31(51.7)$ \\
\hline Nuclear & \\
\hline Location & $36(60.0)$ \\
\hline Rural & $24(40.0)$ \\
\hline Urban & \\
\hline Marital status & $11(18.3)$ \\
\hline Unmarried & $45(75.0)$ \\
\hline Married & $4(6.7)$ \\
\hline Separated/ Divorced & \\
\hline Socio-economic status & $21(35.0)$ \\
\hline Low (Class V) & $34(56.7)$ \\
\hline Middle (Class II, III, IV) & $5(8.3)$ \\
\hline Upper (Class I) & \\
\hline
\end{tabular}

Clinical Profile-Analysis revealed that mean age of onset of alcohol use was 25.03 years (S.D $= \pm 4.26$ ). Duration of use before seeking treatment and total duration of dependence was 13.32 years $(S . D= \pm 6.61)$ and 7.37 years $(S . D= \pm 5.7)$ respectively. Average quantity of alcohol (IMFL, Indian Made Foreign Liquor) consumption per day was $356.83 \mathrm{ml}$. $55 \%$ of patients were severely dependent on alcohol. Further details are given in Table 2.

Table-2: Clinical profile.

\begin{tabular}{|l|c|}
\hline Clinical variable & $\mathbf{n}(\boldsymbol{\%})$ \\
\hline Mean age of onset of use in years \pm S.D. & $25.03 \pm 4.266$ \\
\hline Duration of use before seeking treatment in years \pm S.D. & $13.32 \pm 6.617$ \\
\hline Duration of dependence in years \pm S.D. & $7.37 \pm 5.707$ \\
\hline Time taken to develop dependence in years \pm S.D. & $6.02 \pm 3.10$ \\
\hline Average alcohol intake in ml/ day (IMFL) & $356.83 \pm 159.006$ \\
\hline Quantity of alcohol intake/ day & \\
\hline 90 to 359 ml & $19(31.7)$ \\
\hline 360 and above & $41(68.3)$ \\
\hline SADQ score $>\mathbf{3 0}$ & $33(55)$ \\
\hline Tobacco dependence & \\
\hline Smoking & $33(55.0)$ \\
\hline Chewable & $14(23.3)$ \\
\hline Family history of alcohol dependence & $18(30.0)$ \\
\hline
\end{tabular}


Prevalence and typology of sexual dysfunction-According to ASEX a person is considered to have sexual dysfunction if he has a total score of $\geq 19$ or, has a score $>5$ on any one item or, has a score of $>4$ on any three items of ASEX. Additionally, a score of 4 or more can be used to define sexual dysfunction in a particular domain. Accordingly, $58.3 \%$ of the patients had sexual dysfunction. In terms of domains, highest prevalence was seen for dysfunction in the domain of ability to reach orgasm $(60 \%)$, followed by satisfaction with orgasm $(58.3 \%)$, erection $(56.7 \%)$ and desire was least affected $(30 \%)$. Further details are given in Table 3.

Table-3: Sexual Dysfunction as per ASEX.

\begin{tabular}{|l|c|}
\hline Variables & $\mathbf{n}(\boldsymbol{\%})$ \\
\hline Desire/Drive & $18(30 \%)$ \\
\hline Arousal & $26(43.3 \%)$ \\
\hline Erection & $34(56.7 \%)$ \\
\hline Ability to reach Orgasm & $36(60 \%)$ \\
\hline Satisfaction with Orgasm & $35(58.3 \%)$ \\
\hline ASEX-global scores $(\geq 19)$ & $29(48.33 \%)$ \\
\hline ASEX score 4 on 3 domains but global score of <19 & $5(8.33 \%)$ \\
\hline ASEX score 5 on 1 domain but global score of $<\mathbf{1 9}$ & $1(1.66 \%)$ \\
\hline Total number of patients with sexual dysfunction & $35(58.3 \%)$ \\
\hline
\end{tabular}

As per sexual dysfunction checklist, highest prevalence was seen for dissatisfaction with own sexual function (58.3\%), followed by anorgasmia (56.7\%), difficulty in achieving (48.3\%) and maintaining (53.3\%) erection, premature ejaculation (46.7\%) and frequency dissatisfaction (46.7\%). Further details are given in Table 4.

\section{Table-4: Sexual Dysfunction as per Sexual dysfunction checklist.}

\begin{tabular}{|l|c|}
\hline In the past $\mathbf{1 2}$ months & n (\%) \\
\hline $\begin{array}{l}\text { Has the prospect of having sex with your partner produced such aversion, fear or anxiety that you } \\
\text { avoided any sexual activity (Aversion to sex)? }\end{array}$ & $0(0)$ \\
\hline $\begin{array}{l}\text { Have you had a lack or loss of sexual desire, which has led you to initiating sexual activity with } \\
\text { your partner or engaging in solitary masturbation, at a frequency clearly lower than previous levels } \\
\text { (Low sexual desire)? }\end{array}$ & $23(38.3 \%)$ \\
\hline $\begin{array}{l}\text { Have you had a difficulty in getting an erection sufficient for intercourse (Difficulty achieving } \\
\text { erection)? }\end{array}$ & $29(48.3 \%)$ \\
\hline $\begin{array}{l}\text { Have you had difficulty in maintaining erection (full erection occurs during the early stages of } \\
\text { lovemaking but disappears when intercourse is attempted or before ejaculation if it occurs) } \\
\text { (Difficulty maintaining erection)? }\end{array}$ & $32(53.3 \%)$ \\
\hline $\begin{array}{l}\text { Have you found that frequently (or always) you have ejaculated before you would like to: before } \\
\text { entry? } \\
\text { < } 1 \text { min? } \\
<3 \text { min? (Premature ejaculation) }\end{array}$ & $28(46.7 \%)$ \\
\hline Have you frequently had problems in ejaculating even when erect (Inhibited / delayed ejaculation)? & $20(33.3 \%)$ \\
\hline Have you ever ejaculated without getting full erection (Orgasm with flaccid penis)? & $8(13.3 \%)$ \\
\hline Do you have difficulty in reaching the peak of pleasure at the time of ejaculation (Anorgasmia)? & $34(56.3 \%)$ \\
\hline Have you felt pain in the genitals during sexual intercourse (Coital pain)? & $18(30 \%)$ \\
\hline $\begin{array}{l}\text { Are you satisfied with the frequency of sex (Frequency dissatisfaction)? } \\
\text { Are you satisfied with your sexual relationship with your partner (Dissatisfaction of sexual relation } \\
\text { with partner)? }\end{array}$ & $9(15 \%)$ \\
\hline Are you satisfied with your sexual performance (Dissatisfaction with own sexual function)? & $35(58.3 \%)$ \\
\hline
\end{tabular}

Comparison of socio-demographic and clinical profile of those with and without sexual dysfunction (SD) as per ASEX. 
On socio- demographic variables, those with and without sexual dysfunction as per ASEX did not differ on various parameters, except that mean age at presentation was significantly late for those with sexual dysfunction.

On clinical variables, patients with sexual dysfunction had consumed significantly more quantity of alcohol per day, for longer duration and remained dependent for more years compared to patients without dysfunction. Sexual dysfunction was significantly more common among patients with severe dependence as assessed by SADQ. Tobacco use was not found to be a significant determinant of sexual dysfunction. Further details are given in Table 5.

Table-5: Clinical profile patients with and without sexual dysfunction as per ASEX.

\begin{tabular}{|c|c|c|c|}
\hline Clinical variable & With SD n (\%) & Without SD n (\%) & p- value \\
\hline Mean age of onset of use in years (S.D.) & $25.56 \pm 4.388$ & $24 \pm 4.425$ & 0.197 \\
\hline Duration of use before seeking treatment in years (S.D.) & $14.56 \pm 7.101$ & $10.8 \pm 5.385$ & $0.040^{*}$ \\
\hline Duration of dependence in years (S.D.) & $9.20 \pm 6.788$ & $4.60 \pm 2.958$ & $0.009^{*}$ \\
\hline Time taken to develop dependence in years (S.D.) & $5.52 \pm 2.888$ & $6.20 \pm 3.547$ & 0.422 \\
\hline Average alcohol intake ml/ day (Whiskey/ IMFL) & 410 & 324 & 0.067 \\
\hline \multicolumn{4}{|l|}{ Quantity of alcohol intake/ day } \\
\hline 90 to $359 \mathrm{ml}$ & $7(20)$ & $12(48)$ & $0.022^{*}$ \\
\hline 360 and above & $28(80)$ & $13(52)$ & \\
\hline SADQ score $>30$ & $23(65.71)$ & $10(40)$ & $0.048^{*}$ \\
\hline \multicolumn{4}{|l|}{ Tobacco dependence } \\
\hline Smoking & $17(48.57)$ & $16(64)$ & 0.236 \\
\hline Chewable & $9(25.71)$ & $5(20)$ & 0.606 \\
\hline Family history of alcohol dependence & $12(34.28)$ & $6(24)$ & 0.391 \\
\hline
\end{tabular}

${ }^{*} \mathrm{p}$ value $<0.05$

\section{Discussion}

Sexual dysfunction appears to be common among male subjects with alcohol dependence. $58.3 \%$ of the subjects with alcohol dependence complained of one or more problems with sexual functioning. Various studies done across the globe with sample sizes of 18-816, showed the rates of SD have ranged between $40-95.2 \%$, with rates being consistently much higher in alcoholdependent population than in the healthy controls or alcohol users [4].

As per the review by Grover et al. the common SDs reported were erectile dysfunction followed by premature ejaculation, retarded ejaculation and decreased sexual desire among men [4]. According to the study done by Arackal et al. on Indian population, most common problems were premature ejaculation, low sexual desire and erectile dysfunction. In the same study $14.58 \%$ reported anorgasmia and $19.79 \%$ dissatisfaction with own sexual function [13]. But in our study patients reported inability to reach orgasm (60\%), dissatisfaction with orgasm $(58.3 \%)$ and dissatisfaction with own sexual function $(58.3 \%)$ as the most common problems followed by erectile dysfunction. Many of the

patients may not be aware of the concept of orgasm and may find difficulty in reporting to the psychiatrist compared to decreased sexual desire, erectile dysfunction and premature ejaculation. This might be the possible reason for under reporting of anorgasmia in other studies.

Although studies have tried to characterise the correlates of SD in patients with alcohol dependence, there are very few consistently reported correlates. Advancing age has been reported as one of the consistent correlate of sexual dysfunction in patients with alcohol dependence $[14,15]$. In our study too mean age at presentation for patients with SD was 
significantly late compared to those without SD. Studies have been found the chance of developing SD increases with the high amount of alcohol consumption per day $[13,16]$, longer duration of intake and dependence [17]. Similar results have been found in our study. Higher quantity of alcohol intake may result in greater neurotoxic effects [18] and long term alcohol use may affect male reproductive hormones and semen quality [19].

Although some of the previous studies suggest that comorbid use of tobacco, increases the prevalence of sexual dysfunction in patients with alcohol dependence $[13,20]$, results of this study do not support the same.

Present study focused on small number of alcohol dependent patients attending drug de- addiction and medical services in a tertiary care centre, hence results cannot be generalized to patients with alcohol dependence or use in the community. Future studies should focus on larger sample size and community based sample.

\section{Conclusion}

On the basis of the findings of the present study and existing literature, it can be concluded that SD is highly prevalent in patients with alcohol dependence and all domains of sexual functioning are affected. Hence, the clinicians should routinely enquire about SD and do motivational counselling for patients to abstain from alcohol use. Achieving orgasm being the most important component of sexual functioning and anorgasmia is the most common dysfunction reported by our patients. Longer duration of alcohol consumption and dependence, high levels of intake and sever dependence appeared to be the most significant predictors of developing sexual dysfunction.

Funding: Nil, Conflict of interest: None initiated, Permission from IRB: Yes

\section{References}

1. World Health Organization. WHO Global Status Report on Alcohol and Health. Geneva, Switzerland: WHO;2014. Available at: apps.who.int/iris/bitstream/ 10665/ 112736/1/9789240692763_eng.pdf.

2. Obot IS, Poznyak V, Monteiro M. From basic research to public health policy: WHO report on the neuroscience of substance dependence. Addict Behav. 2004 Sep;29(7):1497-502.
3. Gelder M, Gath D, Mayon R, Cowen P. Etiology of sexual dysfunction. In: Oxford Text book of Psychiatry, $3^{\text {rd }}$ ed. Oxford, UK: Oxford University Press, 1996.

4. Grover S, Mattoo SK, Pendharkar S, Kandappan V. Sexual dysfunction in patients with alcohol and opioid dependence. Indian J Psychol Med. 2014 Oct;36(4): 355-65. doi: 10.4103/0253-7176.140699.

5. Fahrner EM. Sexual dysfunction in male alcohol addicts: Prevalence and treatment. Arch Sex Behav. 1987 Jun;16(3):247-57.

6. Fahrner EM. Sexual dysfunction in male alcohol addicts: prevalence and treatment. Arch Sex Behav. 1987 Jun;16(3):247-57.

7. World Health Organization. Alcohol Use and Sexual Risk Behaviour: A Cross-Cultural Study in Eight Countries. Geneva: World Health Organization; 2005.

8. Peugh J, Belenko S. Alcohol, drugs and sexual function: A review. J Psychoactive Drugs. 2001 JulSep; 33(3):223-32.

9. Powers AD, Gleason ME, Oltmanns TF. Symptoms of borderline personality disorder predict interpersonal (but not independent) stressful life events in a community sample of older adults. J Abnorm Psychol. 2013 May;122(2):469-74. doi: 10.1037/a0032363.

10. Stockwell T, Murphy D, Hodgson R. The severity of alcohol dependence questionnaire: its use, reliability and validity. Br J Addict. 1983 Jun;78(2):145-55.

11. World Health Organization. The ICD-10 classification of mental and behavioral disorders: Diagnostic criteria for research. World Health Organization: Geneva;1993.

12. McGahuey CA, Gelenberg AJ, Laukes CA, Moreno FA, Delgado PL, McKnight KM et al. The Arizona Sexual Experience Scale (ASEX): reliability and validity. J Sex Marital Ther. 2000 Jan-Mar; 26(1): 25-40.

13. Arackal BS, Benegal V. Prevalence of sexual dysfunction in male subjects with alcohol dependence. Indian J Psychiatry. 2007 Apr;49(2):109-12. doi: 10. 4103/ 0019-5545.33257. 
14. Hartford JT, Samorajski T. Alcoholism in the geriatric population. J Am Geriatr Soc. 1982 Jan; 30 (1):18-24.

15. O'Donnell AB, Araujo AB, McKinlay JB. The health of normally aging men: The Massachusetts Male Aging Study (1987-2004). Exp Gerontol. 2004 Jul;39 (7):975-84.

16. Rosen RC. Alcohol and drug effects on sexual response: Human experimental and clinical studies. Annu Rev Sex Res. 1991;2:119-79

17. McCambridge J, Mitcheson L, Hunt N, Winstock A. The rise of Viagra among British illicit drug users: 5- year survey data. Drug Alcohol Rev. 2006 Mar; 25(2):111-3.

18. Villalta J, Estruch R, Antunez E, Valls J, UrbanoMarquez A. Vagal neuropathy in chronic alcoholics: Relation to ethanol consumption. Alcohol Alcohol. 1989; 24(5):421-8.

19. Muthusami KR, Chinnaswamy P. Effect of chronic alcoholism on male fertility hormones and semen quality. Fertil Steril. 2005 Oct;84(4):919-24.

20. Girish N, Kavita R, Gururaj G, Benegal V. Alcohol use and implications for public health: patterns of use in four communities. Indian J Community Med. 2010 Apr; 35(2):238-44. doi: 10.4103/0970-0218.66875.

\section{How to cite this article?}

Anil Kumar B.N, Shalini M, Sanjay Raj G, Prasannakumar D.R. Prevalence, typology and clinical correlates of sexual dysfunction among men with alcohol dependence syndrome. Int J Med Res Rev 2016;4(10):18261832.doi:10.17511/ijmrr. 2016.i10.19. 